\title{
Potential Non-toxic Indian Medicinal Plants may Use as a Traditional Medicine to Treat Covid-19 and Opportunistic Fungal Infections
}

\section{King Solomon Ebenezer*, Tamilselvan Chidambaram, Rekha Maniva- nan, Venkatadri Babu, Abarna Punniyamoorthy and Mangaiyarkarasi Palanisamy}

Bioscience Research Foundation, Chennai, Tamilnadu, India

*Corresponding Author: King Solomon Ebenezer, Bioscience Research Foundation, Chennai, Tamilnadu, India. E-mail: solu.king@gmail.com
Received: June 28, 2021

Published: July 26, 2021

(C) All rights are reserved by King Solomon

Ebenezer., et al.

\begin{abstract}
The severe acute respiratory syndrome (SARS) Coronavirus virus (SARS CoV2) pandemic, which originated in Wuhan, China and spread to all countries, has had a huge impact on the global human population. As a result of environmental conditions and human immunity-based infection, virus strains have recently changed and formed a virulent new strain that affects people. Scientists are having difficulty controlling the changed virulence strain in terms of vaccine production. In ancient times, medicinal plant extracts were used directly for sickness suppression and eradication. As a result, this mode is appropriate for eradicating coronavirus from the human body. India is the wealthiest country in the world, particularly in terms of medicinal plants. Some medicinal plants have great potential secondary metabolites for combating viral and fungal diseases while also being nontoxic. With a high rate of success, therapeutic plant items have recently become popular in the fight against the threatening COVID-19 disease. Under these circumstances, finding a medicine for a lethal disease is vital in order to lower death rates and save human lives. Gymnema sylvestre has shown promising action against viruses and fungi, therefore it may be examined further in the drug development process.
\end{abstract}

Keywords: Coronavirus; LD50; Non-toxic; Medicinal Plant; Viral Infections; Immunity; Mucormycosis

\section{Introduction}

In the early 1960s, two strains of a novel virus, 229E and 0C43, were discovered in the respiratory tracts of people who had a common cold. Both strains had pleomorphic, membrane-coated, and club-shaped surface projections, despite being found by different scientists. These viruses, along with other animal viruses with similar appearance, were later grouped into a new genus and designated coronavirus in the late 1960s. This group of viruses has infected mammals and birds throughout history, including rats, mice, dogs, cats, turkeys, calves, rabbits, and pigs. Coronavirus infection in humans occurred at any age and most common in children causing a variety of respiratory illness including mild upper respiratory tract infection, common cold and often asthma and chronic bronchitis. Previously in the year 2002-2003, a severe acute respiratory syndrome caused by a novel coronavirus lead to an epidemic disease and later termed as SARS coronavirus. In the following years, new strains of coronavirus NL63, NH and HKU1 were discovered associated with respiratory illness coronavirus. In 2012, another novel coronavirus caused epidemic disease in Middle East and Europe and the disease termed as MERS coronavirus. Both the SARS and MERS coronavirus thought to be spread from animals, the former from Himalayan civets and the latter from camels [1].

The present coronavirus infection emerged in 2019 in China presumed to be transmitted from bat has spread to all the countries 
around the globe and declared as a pandemic disease. The genome of the novel coronavirus is mostly similar to the SARS coronavirus and hence termed as SARS CoV2 and the disease was named as COVID-19 by World Health Organization [2]. Since last year, in India and other countries the 1st wave, 2nd wave of SARS coronavirus 2 infection continuing in the human population and 3rd wave to be expected on forth coming days. The infection rate and mortality rate had been alarmingly increasing all over the world. In order to reduce the spreading of infection and death rate, all around the world each country has taken measures such as lockdown, restrictions of public affairs, closing the international borders, etc. In other point of view world economic was also affected. Even though these measures in effect the virus is still spreading and has become more virulent than that of when it was emerged.

The scientists from Centre for Cellular and Molecular Biology of the Council of Scientific and Industrial Research (CSIR-CCMB, Hyderabad, India) identified genetically unique cluster 'Clade A3i and A2a' of novel coronavirus in India. At the time of outbreak in February 2020 the Clade A3i identified, which comprises of $41 \%$ of all SARS-CoV2 genomes from Indian samples, and 3.5\% of global genomes. Now A2a is emerging predominant coronavirus clade in India, out of the 213 genomes analyzed showed $62 \%$ were A2a and $41 \%$ of the A3i clade. So day by day the emergence and virulence activity of the mutant Covid 19 virus is giving danger to humans and trouble to scientist.

Previous research has identified 22 traditional medicinal plants with potential antiviral action [3]. According to a similar report, antiviral, anti-inflammatory, and immuno-modulatory actions of AYUSH herbal formulations may help to lessen the severity of the disease [4]. This review examines the effects of Indian traditional medicinal plants on viral and opportunistic fungal infections, as well as their acute toxicological effects.

\section{SARS COV-2 virus infection: A better understanding}

Coronavirus is a positive sense single strand RNA virus and it is composed of lipid bilayer envelope proteins. The SARS COV-2 virus enters in to human through the attachment of envelope spike protein (S protein) with a human membrane receptor (ACE2). After binding the RNA genome of virus the 5'methylated and 3' polyadenylated tail acts as a mRNA and gets translated with the human ribosomes.
During translation, RNA dependent RNA polymerase, RNA helicase, and Exoribonuclaease each produce proteins involved in replication, transcription and recombination process. The progeny virus with positive sense RNA assembles and released from the host through exocytosis and infects other cells [5].

\section{Preventive actions}

The coronavirus prevention approach is limiting the spread of cases. It's logically straightforward, and everyone knows to wash their hands frequently with soap or disinfectants. Maintaining a strict social distance from the individual, Covering nose and mouth with a mask helps prevent the exposure to virus. When confronted with unavoidable situations, the person should stop touching eyes, nose, or mouth with your hands. Cover your nose and mouth with your bent elbow while coughing. Stay at home and self-quarantine instead of travelling. If the preventive measures strictly adhered, the virus will not spread to another and can save the human lives [6] (Figure 1).

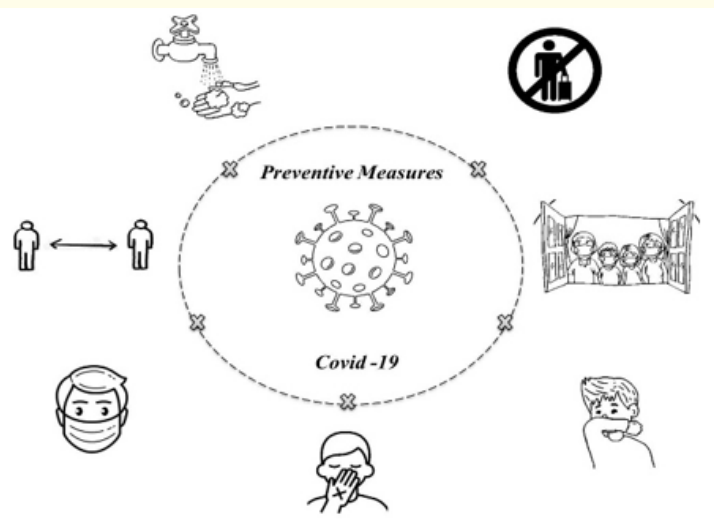

Figure 1: Preventive measure to control Covid-19.

\section{Indian medicinal plants}

India has the richest source and leading in the medicinal plants wise compared to other countries. In this regard, there are an estimated 40,000 plant species, each with its own flora, and different medicinal plant species which are distributed across many diverse geographical and climatic zones. Those species were widely used in traditional Indian medical systems [7]. The lack of a specialized medicine to treat the mutant COVID-19 disease will result in a high 
mortality rate, particularly among those with weakened immune systems. Many research institutes and scientists are still working on developing a new vaccination or immune-related medicine to combat altered strains. The utilization of secondary metabolites from plants used in the development of poly herbal medicine to treat viral diseases may help to control coronavirus infection in humans [8]. Medicinal plants are the backbone of Indian traditional medicine system and have a long history of usage in India especially in Tamilnadu as 'Sidda Maruthuvam'. A recent scientific improvement has been helpful for scientists in establishing and proving the efficacy of the medicinal plants with the respective therapeutic use to the community. In this regard, table 1 enlists the proven potential medicinal plants with activity against life threatening viral diseases, the medicinal plants with efficacy to treat the common symptoms exhibited in any viral diseases such as fever cough asthma and also the medicinal plants that can modulate the immune system and boosts up the body defense system against pathogen attack. The table also provides the acute toxicity data of those medicinal plants in terms of $\mathrm{LD}_{50}$. Acute toxicity is the first test conducted for the safety assessment for any chemical including pharmaceuticals before human consumption. The test utilizes animal model to administrate through oral, dermal or inhalation route followed by absorption and distribution throughout the body that elicits any systemic toxicity if present [9]. The mentioned medicinal plants have proven to be well tolerated systematically as the LD50 values were above the regulatory limits and are safe for human consumption. Development of a potential drug from the medicinal plant thus can prove useful in the long run of Coronavirus battle.

\begin{tabular}{|c|c|c|c|c|}
\hline Medicinal Plants & \begin{tabular}{|c}
$\begin{array}{c}\text { Medicinal } \\
\text { Use }\end{array}$ \\
\end{tabular} & $\begin{array}{l}\text { Refer- } \\
\text { ences }\end{array}$ & $\begin{array}{c}\mathrm{LD}_{50}(\mathrm{mg} / \\
\mathrm{kg} \text { b.wt) }\end{array}$ & $\begin{array}{l}\text { Refer- } \\
\text { ences }\end{array}$ \\
\hline Pergularia daemia & HBV & {$[10]$} & 2500 & {$[11]$} \\
\hline Gymnema sylvestre & Malaria & {$[12]$} & 3990 & [13] \\
\hline Ocimum sanctum & Malaria & [14] & $>2000$ & [15] \\
\hline Annona reticulata & HSV-1 & [16] & $>2000$ & [17] \\
\hline Bauhinia purpuria & HSV & [18] & $>2000$ & [19] \\
\hline Momordica charantia & HIV & {$[20]$} & $>5000$ & {$[21]$} \\
\hline $\begin{array}{l}\text { Andrographis } \\
\text { paniculata }\end{array}$ & HIV & {$[22]$} & 5000 & [23] \\
\hline Vetiveria zizanioides & Dengue & {$[24]$} & 2985 & {$[25]$} \\
\hline Cyperus rotandus & HSV & {$[26]$} & 5000 & [27] \\
\hline Terminalia chebula & HSV-2 & [28] & 5000 & [29] \\
\hline Solanum trilobatum & HSV & {$[30]$} & 2000 & [31] \\
\hline Picrrorizha kurora & HBV & [33] & 2000 & {$[34]$} \\
\hline
\end{tabular}

Table 1: List of medicinal plant with toxicity properties.

\section{Recent opportunistic infection: Mucormycosis}

Coronavirus 2 (SARS-CoV-2) has recently been linked to a variety of opportunistic bacterial and fungal illnesses. Recently, India has been battling covid 19 as well as fungal infections, with illness and fatality rates growing day by day. This is a nightmare for scientists and other clinicians working on medicine development and illness control. Mucormycosis is most common in those who have health difficulties, diabetes, or who are immunocompromised. Paltauf initially identified phycomycosis or zygomycosis in 1885, and Baker, an American pathologist, created the term Mucormycosis in 1957 to characterise an aggressive Rhizopus infection [35].

\section{Black fungus}

Mucormycosis is a serious but rare fungal infection caused by a group of molds called mucormycetes. These molds live throughout the environment. Mucormycosis, an angioinvasive disease caused by mold fungi of the genus Rhizopus, Mucor, Rhizomucor, Cunninghamella and Absidia [36].

In the current situation, the globe has begun to declare a "black fungus" epidemic, with incidences of the lethal uncommon illness increasing in people recuperating from Covid-19 infection. Mucormycosis is a fungal illness that has a $50 \%$ death rate.

The Mucormycosis usually often affects people in the nose first, and then spreads to the eyes. It is typically a rare disease; however it is now a prevalent opportunistic infection among patients with covid-19. Hence, current meta-data analysis of more than 7,200 persons in India have been diagnosed with mucormycosis and 219 patients are died. There have been no research activities done to prove the infectious agents. The surge in black fungus infections has been related to an overuse of steroids in the treatment of the coronavirus, which can severely impair the immune system if taken for an extended length of time.

The guardian news reported on 21 May, 2021 that the mould enters the body and then appears around the nose and eye sockets, blackening the nose, and eventually moving fatally into the brain if not halted. The fungus can typically be fought off by healthy people, but it can spread quickly in those aged and weakened immune systems (https://www.theguardian.com/world/2021/may/21/ mucormycosis-black-fungus-disease-linked-covid-spreads-india). Globally, many researchers and physicians searched for the drug to control and eradicate the black fungus. Recently, one of the leading pharmaceutical company Genetik Lifesciences, based in Wardha, gained FDA approval to make the Amphotericin B injectable for black fungus infection for COVID-19 patients published on Swara- 
jya magazine on May 15, 2021 (https://swarajyamag.com/insta/ genetik-lifesciences-to-produce-affordable-aphotericin-b-injection-to-treat-black-fungus-infection-in-covid-patients).

\section{Yellow fungus}

Another mould suspected of infecting COVID 19 patients is Aspergillus niger. It's a common mould that can be found both indoors and outdoor. This fungal infection would be lethal in immunocompromised people. Invasive infections are increased by neutropenia and/or corticosteroid therapy, Aspergillus fumigatus accounts for majority of it. Inhalation of airborne conidia is the mode of transmission [37]. Aspergillus niger after transmission binds to fibrinogen and laminin in the alveolar basement membrane. Even though the macrophages in the human immune system can swallow and kill conidia; the fungi releases gliotoxin, that helps the organism evade phagocytosis. However, Neutrophils can cling to hyphae and destroy them. In condition neutrophils are overwhelmed by hyphae, leads to infiltration of pulmonary and vascular tissue, causing thrombosis and necrosis, as well as hematogenous dissemination (to other organs including brain). The fungal infection will harm the lungs and other organs in immunocompromised patients, resulting in invasive aspergillosis, a fungal disease [38].

\section{White fungus}

Another growing opportunistic infection in COVID19 patients is Candida auris. The origins of this fungal outbreak, according to the $\mathrm{CDC}$, could be attributable to changes in normal infection control methods during the COVID-19 pandemic, such as reduced availability of gloves and gowns, or reuse of these items, as well as changes in cleaning and disinfection techniques. The infection's symptoms differ depending on where Candida auris is found in the body. It can appear in a number of locations, including an open wound, the bloodstream, or the ear. Fever and chills are common symptoms [39].

\section{Risks and control measures}

The possible risk of mucormycosis in the Covid infected patients, with use of high steroids and humidified oxygen ventilators during Covid 19 treatment [40]. Precautions should be required to maintain a normal blood sugar level, and physicians should avoid overusing steroids to treat Covid 19 individuals' with signs of infection (Figure 2).

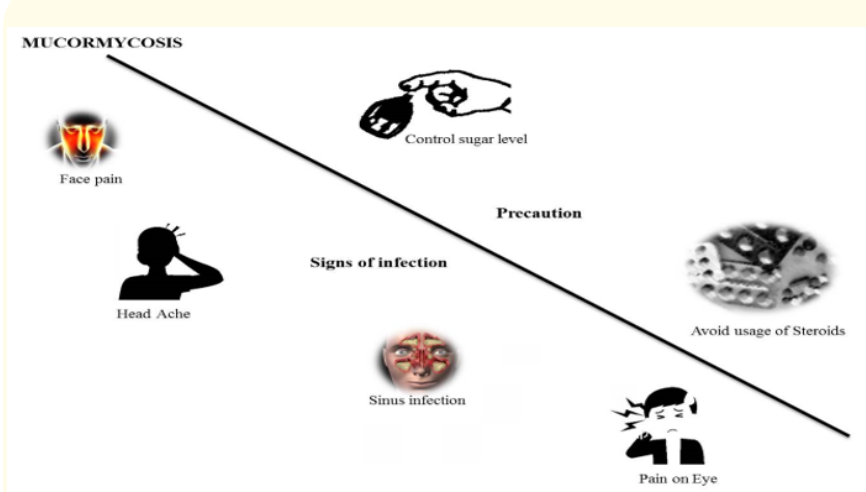

Figure 2: Signs of Infection and Precaution Mode for Mucormycosis.

\section{Medicinal plant for fungal infection}

Gymnema sylvestre is a traditional medicinal plant of Apocynaceae family, which is widely utilised in Ayurvedic medicine [41]. The plant has a wide spectrum of medicinal characteristics that are used to treat diabetes, diuretic, anemia, osteoporosis, hypercholesterolemia, arthritis, cardiopathy, asthma, viral and fungal infections, constipation and an anti-inflammatory agent [42]. Gymnemic acids' is the bioactive component of the plant Gymnema sylvestre, a triterpenoid saponins, which interact and inhibit illness [43]. The plant has proven efficacy against the $C$. albican, the now emerging fatal opportunistic infection of coronavirus. The systemic infection by $C$. albican involves the transition from yeast or pseudohyphal states to the hyphal growth state. This transitioned form causes a more deep infection and evades the immune system [44]. Gymnema sylvestre plant phytochemicals, Gymnemic acids' exhibited a strong inhibitory action of the critical hyphae transition in $C$. albican and also exerted the inhibitory action in non-mammalian model infected with Candida. The inhibitory action was also effective in serum containing medium and also the plant molecules was non-toxic to worms and mammalian cells. Additionally, the plant molecules also exhibited growth inhibitory action against another virulent opportunistic infection, Aspergillus [45]. Previous research reported the significant antiinfluenza activity of gymnemic acid fractions in mice model [46]. Secondary metabolites like alkaloids and terpenoids of medicinal plants involves in the defensing activity against some viruses HBV, HSV, Dengue, and influenza [47]. The plant Gymnema sylvestre has potential antifungal antiviral efficacy 
especially in serum with non-toxicity to mammalian cells can be an effective drug candidate for Coronavirus and opportunistic fungal infections (Figure 3). Previously reported synergetic compositions of some traditional medicinal plants may pose to be used against the single stranded coronavirus [48].
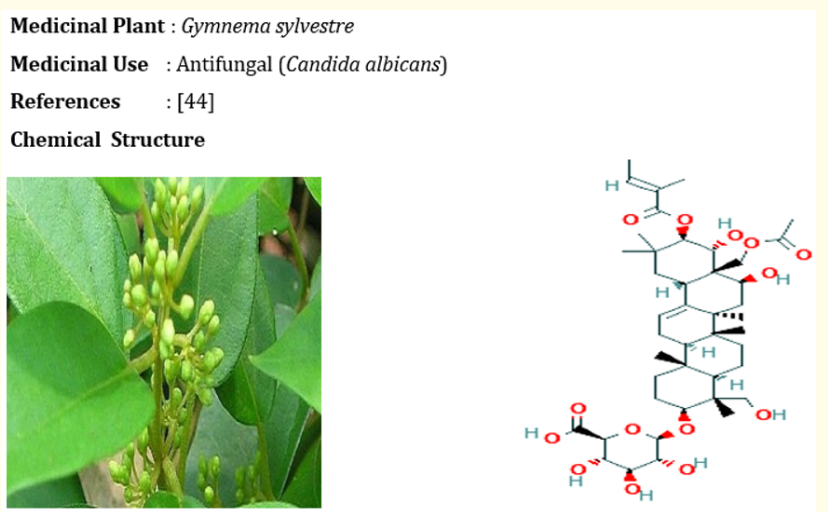

Figure 3: Chemical structure of Gymnemic acid (Source: Pubchem).

\section{Conclusion}

India is second most infected country from COVID-19 disease. In this situation, India is fighting to use different strategies to overcome from dangerous COVID-19 pandemic. Under these circumstances, finding a medicine/drug for a lethal disease is vital in order to lower death rates and save human lives from virus and other diseases. Several medicinal plants were reported for the antiviral activities against viruses, but the medicinal plant Gymnema sylvestre has reported to have the most promising antiviral and anti-fungal properties, which might be investigated further in vitro and in vivo research. In this concern, to the issues, a foremost important is to find a drug to control coronavirus spreading, the use of already available potential secondary metabolites from the Indian medicinal plants for prevention of viral based diseases and fungal based opportunistic disease through ethno-pharmacologically will lead a new path in drug development.

\section{Acknowledgement}

The authors are grateful to Bioscience Research Foundation scientists for their invaluable support with the literature review and manuscript drafting.

\section{Conflict of Interest}

The authors declare that there is no conflict of interests.

\section{Bibliography}

1. Saif LJ. Animal coronaviruses: Lessons for SARS. Learning from SARS: Preparing for the Next Disease Outbreak. The National Academies Press, Washington, DC. 26 (2004): 138-149.

2. World Health Organization. "Global status report on alcohol and health 2018". World Health Organization (2019).

3. Singh RS., et al. "Promising traditional Indian medicinal plants for the management of novel Coronavirus disease: A systematic review". Phytotherapy Research (2021): 1-29.

4. Ahmad S., et al. "Indian Medicinal Plants and Formulations and Their Potential Against COVID-19-Preclinical and Clinical Research". Frontiers in Pharmacology 11 (2021): 578970.

5. Belouzard S., et al. "Mechanisms of coronavirus cell entry mediated by the viral spike protein". Viruses 4.6 (2012): 10111033.

6. GuNER HR., et al. "COVID-19: Prevention and control measures in community". Turkish Journal of Medical Sciences 50 (2020): 571-577.

7. Vimalanathan S., et al. "Medicinal plants of Tamil Nadu (Southern India) are a rich source of antiviral activities". Pharmaceutical Biology 47.5 (2009): 422-429.

8. Kaur I., et al. "Coronavirus disease (COVID-19): An updated review based on current knowledge and existing literature for dermatologists". Dermatologic Therapy 33.4 (2020): e13677.

9. Saganuwan SA. "The new algorithm for calculation of median lethal dose (LD50) and effective dose fifty (ED50) of Micrarus fulvius venom and anti-venom in mice". International Journal of Veterinary Science and Medicine 4.1 (2016): 1-4.

10. Karthishwaran K., et al. "Phytochemical investigation of methanolic extract of the leaves of Pergularia daemia". Journal of Biological Sciences 10.3 (2010): 242-246.

11. Vaithiyanathan V and Mirunalini S. "Assessment of antioxidant potential and acute toxicity studies of whole plant extract of pergularia daemia (Forsk)". Toxicology International 22.1 (2015): 54 . 
12. Khanna R., et al. "Assessment of health-related quality of life among primary caregivers of children with autism spectrum disorders". Journal of Autism and Developmental Disorders 41.9 (2011): 1214-1227.

13. Ogawa Y., et al. "Gymnema sylvestre leaf extract: a 52-week dietary toxicity study in Wistar rats. Shokuhin eiseigaku zasshi". Journal of the Food Hygienic Society of Japan 45.1 (2004): 8-18.

14. Prakash PA and Gupta N. "Therapeutic uses of Ocimum sanctum Linn (Tulsi) with a note on eugenol and its pharmacological actions: a short review". Indian Journal of Physiology and Pharmacology 49.2 (2005): 125.

15. Ghatule RR., et al. "Protective effects of Aegle marmelos fruit pulp on 2, 4, 6-trinitrobenzene sulfonic acid-induced experimental colitis". Pharmacognosy Magazine 10 (2014): S147.

16. Yunita MN., et al. "Antiviral Activity of Ethanolic Extract of Srikaya Seeds (Annona squamosa L.) Against Avian Influenza Virus". Indian Veterinary Journal 96 (2019): 26-29.

17. Shivanna LM., et al. "Acute Toxicity Study of Annona reticulata Leaves Extract in Swiss Albino Mice". International Journal of Pharmaceutical Investigation 9.2 (2019): 71-75.

18. Faral-Tello P., et al. "Cytotoxic, virucidal, and antiviral activity of South American plant and algae extracts". The Scientific World Journal (2012).

19. Makadiya VS., et al. "Acute and 28-day repeated dose oral toxicity of Bauhinia variegata (Caesalpiniaceae) stem bark extract". Journal of Herbs, Spices and Medicinal Plants 21.2 (2015): 161172.

20. Zahan S. "Evaluation of phytochemical and pharmacological properties of seeds of Momordica charantia". Avicenna Journal of Phytomedicine 10.5 (2020): 448.

21. Abdillah S., et al. "Acute and Subchronic Toxicity of Momordica Charantia L Fruits Ethanolic Extract in Liver and Kidney". Systematic Reviews in Pharmacy 11.12 (2020): 249-255.

22. Jayakumar T., et al. "Experimental and clinical pharmacology of Andrographis paniculata and its major bioactive phytoconstituent andrographolide". Evidence-Based Complementary and Alternative Medicine (2013).

23. Worasuttayangkurn L., et al. "Acute oral toxicity evaluation of Andrographis paniculata-standardized first true leaf ethanolic extract". Toxicology Reports 6 (2019): 426-430.
24. Luqman S. "Investigations on biological activity of Vetiveria zizanioides L. Nash, a palingenesis of some important findings in miracle grass". Nature Proceedings 7 (2012): 1.

25. Tripathi BK and Srivastava AK. "Diabetes mellitus: complications and therapeutics". Medical Science Monitor 12.7 (2006): RA130-147.

26. Kamala A., et al. "Plants in traditional medicine with special reference to Cyperus rotundus L.: a review". 3 Biotech 8.7 (2018): 1-1.

27. Thanabhorn S., et al. "Acute and subacute toxicities of the ethanol extract from the rhizomes of Cyperus rotundus Linn". Mahidol University Journal of Pharmaceutical Sciences 32 (2005): 15-22.

28. Kesharwani A., et al. "Anti-HSV-2 activity of Terminalia chebula Retz extract and its constituents, chebulagic and chebulinic acids". BMC Complementary and Alternative Medicine 17.1 (2017): 1-1.

29. Panunto W., et al. "Acute and chronic toxicity studies of the water extract from dried fruits of Terminalia chebula Rezt. in rats". International Journal of Applied Research in Natural Products 3.4 (2010): 36-43.

30. Anandakumar S., et al. "Potential phytopharmaceutical constituents of Solanum trilobatum L. as significant inhibitors against COVID-19: Robust-binding mode of inhibition by molecular docking, PASS-aid bioactivity and ADMET investigations". (2020).

31. Parasuraman S., et al. "Ameliorative effect of curcumin on olanzapine-induced obesity in Sprague-Dawley rats". Pharmacognosy Research 9.3 (2017): 247.

32. Arbab AH., et al. "In vitro evaluation of novel antiviral activities of 60 medicinal plants extracts against hepatitis B virus". Experimental and Therapeutic Medicine 14.1 (2017): 626-634.

33. Krishna S., et al. "Time-dependent behavioral, neurochemical, and metabolic dysregulation in female C57BL/6 mice caused by chronic high-fat diet intake". Physiology and Behavior 157 (2016): 196-208.

34. Bell S and Mahoney L. "Mucormycosis: a case study". Critical Care Nurse 20.1 (2000): 18.

35. Spellberg B., et al. "Safety and outcomes of open-label deferasirox iron chelation therapy for mucormycosis". Antimicrobial Agents and Chemotherapy 53.7 (2003): 3122. 
36. Challa S. "Pathogenesis and pathology of invasive aspergillosis". Current Fungal Infection Reports 12.1 (2018): 23-32.

37. Dagenais TR and Keller NP. "Pathogenesis of Aspergillus fumigatus in invasive aspergillosis". Clinical Microbiology Reviews 22.3 (2009): 447.

38. Hogan LH., et al. "Virulence factors of medically important fungi”. Clinical Microbiology Reviews 9.4 (1996): 469.

39. Francois JM., et al. "Use of atomic force microscopy (AFM) to explore cell wall properties and response to stress in the yeast Saccharomyces cerevisiae". Current Genetics 59.4 (2013): 187196.

40. Mehta P., et al. "COVID-19: consider cytokine storm syndromes and immunosuppression". The Lancet 395.10229 (2020): 1033-1034.

41. Christopoulos M V., et al. "Germplasm diversity and genetic relationships among walnut (Juglans regia L.) cultivars and Greek local selections revealed by Inter-Simple Sequence Repeat (ISSR) markers". Scientia Horticulturae 125.4 (2010): 584-592.

42. Tiwari P., et al. "Phytochemical and pharmacological properties of Gymnema sylvestre: An important medicinal plant". BioMed Research International (2014): 1-18.

43. Yoshikawa K., et al. "Antisweet Natural Products. V. Structures of Gymnemic acids VIII-XII from Gymnema sylvestre R. Br". Chemical and Pharmaceutical Bulletin 40 (1992): 1779-1782.

44. Noble SM., et al. "Systematic screens of a Candida albicans homozygous deletion library de-couple morphogenetic switching and pathogenicity". Nature Genetics 42 (2010): 590-598.

45. Vediyappan Govindsamy., et al. "Gymnemic Acids Inhibit Hyphal Growth and Virulence in Candida albicans". PLOS ONE (2013).

46. Joseph E Sinsheimer., et al. "Isolation and antiviral activity of the gymnemic acids". Birkhauser-Verlag; Birkhauser Verlag; Springer Science+ Business Media (1968).

47. King Solomon Ebenezer., et al. "Plant Secondary Metabolites of Antiviral Properties a Rich Medicinal Source for Drug Discovery: A Mini Review". Journal of Drug Delivery and Therapeutics 9.5 (2019): 161-167.
48. King Solomon Ebenezer, et al. "Synergistic Compositions of Traditional Medicine (SIDDHA) against Perilous + ssRNA Coronavirus a Future Alternative Medicine - A Mini Review". Acta Scientific Pharmaceutical Sciences 5.4 (2021): 55-66.

\section{Volume 5 Issue 8 August 2021 \\ (C) All rights are reserved by King Solomon Ebenezer., et al.}

